\title{
Sobre a ideia de ensino do movimento dialógico-problematizador: para pensar o "se movimentar"
}

On the idea of teaching the dialogical-problematizing movement: to think about "se movimentar"

Sobre la idea del enseñar movimiento vía opción dialógica-problematizadora: para reflexionar sobre "se movimentar"

Bruno Nascimento de Siqueira ${ }^{\mathrm{I}}$

\section{Resumo}

As problemáticas que permeiam o ensinar e o aprender sempre atravessaram a área da Educação Física. A ideia de aprendizagem do "se movimentar" pelo ensino dialógico-problematizador aparece, mesmo que em parte, do ato de Elenor Kunz encontrar em Paulo Freire princípios importantes para (re)pensar o ensino da Educação Física nas escolas do Brasil (KUNZ, 1991). O presente texto tem como pressuposto central a seguinte pergunta: o que quer dizer Elenor Kunz ao se referir a um ensino de movimento dialógico-problematizador? E almeja responder, sobretudo, ao que se propõe essa concepção de ensino do movimento. Portanto, é uma reflexão que consiste em retomar e (re)construir conceitos, teorias e ideias, buscando ampliar as discussões. Nesse trajeto, é recuperada a tradição holandesa e alemã de movimento humano (Sich bewegen). Por fim, retoma a ideia de ensino do movimento dialógico-problematizador, no sentido de continuar pensando os desafios em torno do ensinar e do aprender no contemporâneo.

Palavras-chave: Educação Física; Ensino; Dialógico-Problematizador

\begin{abstract}
The problems that permeate teaching and learning have always crossed the area of Physical Education. The idea of learning about "se movimentar" through dialogical-problematizing teaching appears, even if in part, from the act of Elenor Kunz finding in Paulo Freire important principles for (re)thinking the teaching of Physical Education at school (KUNZ, 1991). This text has as its central thesis the question about what does Elenor Kunz mean when he is referring to a teaching of dialogical-problematizing movement? And it aims to answer, above all, what this movement teaching conception proposes. Therefore, it is a theoretical investigation, which consists of (re)building concepts, theories and ideas, seeking to expand the discussions. Along this path, the Dutch and German tradition of human movement is recovered (Sich bewegen). Finally, it resumes the idea of teaching the dialogical-problematizing movement, in the sense of continuing to think about the challenges surrounding teaching and learning in the contemporary.
\end{abstract}

Keywords: Physical Education; Teaching; Dialogical-Problematizing

${ }^{\text {I } U n i v e r s i d a d e ~ F e d e r a l ~ d e ~ S a n t a ~ C a t a r i n a ~-~ e-m a i l: ~ m r b r u n o n a s c i m e n t o @ g m a i l . c o m ~-~ E n d e r e c ̧ o: ~ T v . ~ S a ̃ o ~ B e n t o ~-~ I t a c o r u b i, ~ F l o r i a n o ́ p o l i s ~-~ S C, ~ B r a s i l ~-~ C E P: ~}$ 88034-250. 


\section{Resumen}

Los problemas que impregnan la enseñanza y el aprendizaje siempre han traspasado el ámbito de la Educación Física. La idea de aprender a "se movimentar" a través de la enseñanza dialógico-problematizadora surge, aunque sea en parte, del acto de Elenor Kunz encontrar en Paulo Freire principios importantes para (re) pensar la enseñanza de la Educación Física en las escuelas de Brasil (KUNZ, 1991). Este texto tiene como tesis central la pregunta: sobre qué quiere decir Elenor Kunz al referirse a una enseñanza del movimiento dialógico-problematizador? Y pretende dar respuesta, sobre todo, a lo que propone esta concepción de la enseñanza del movimiento. Por tanto, se trata de una investigación teórica, que consiste en (re) construir conceptos, teorías e ideas, buscando ampliar las discusiones. Por este camino, se recupera la tradición holandesa y alemana de movimiento humano (Sich bewegen). Finalmente, retoma la idea de enseñar movimiento vía opción dialógico-problematizador, en el sentido de seguir pensando en los desafíos que permean la enseñanza y el aprendizaje en la actualidad.

Palabras clave: Educación física; enseñar; dialógica-problematizadora

\section{Introdução}

As problemáticas que permeiam o ensinar e o aprender sempre atravessaram a área da Educação Física. Afinal, como se ensina e como se aprende? Diversas estratégias foram arregimentadas de modo a buscar suprir tais desafios, principalmente no horizonte dos esportes. Foi no advento do espectro que ocorreu o chamado "movimento renovador", que, na Educação Física como um todo, enfrentou questionamentos e reflexões, de modo a ser entendida, ao menos por parcela de professores e professoras, enquanto área de conhecimento, e, portanto, disciplina pedagógica (SOARES et al., 1992). Dessa forma, o ensino na Educação Física deveria abranger, enquanto totalidade, a cultura corporal, ou como opta Kunz, cultura de movimento (KUNZ, 1989, 1991). Sendo o esporte parcela importante da esfera que corresponde à cultura de movimento, deveria, portanto, passar por uma "transformação didático-pedagógica" (KUNZ, 1994) para encontrar suas potencialidades e finalidades educacionais, bem como sua legitimidade na esfera escolar.

A ideia de aprendizagem do "se movimentar", por um ensino dialógico-problematizador aparece, mesmo que em parte, do ato de Elenor Kunz em encontrar em Paulo Freire princípios importantes para (re)pensar o ensino da Educação Física nas escolas do Brasil (KUNZ, 1991). O presente texto tem como pressuposto central a seguinte pergunta: o que quer dizer Elenor Kunz ao se referir a um ensino de movimento dialógico-problematizador? E almeja responder, sobretudo, ao que se propõe essa concepção de ensino do movimento.

Nas próximas páginas é apresentada uma reconstrução do cenário que possibilitou, a Elenor Kunz, colocar em evidência as questões em torno dos problemas do ensinar e do aprender na Educação Física escolar. Nesse trajeto, é recuperada a tradição holandesa e alemã de movimento humano (Sich bewegen). 
Esse processo permitiu apresentar conceitos de Paulo Freire, a partir de Elenor Kunz, como a proposta de ação dialógica e problematização dos movimentos. Por fim, retoma a noção de ensino do movimento dialógico-problematizador, no sentido de continuar pensando os desafios em torno do ensinar e do aprender no contemporâneo.

\section{Educação física: ensino e mudanças}

O livro "Educação Física: Ensino \& Mudanças", de Elenor Kunz, teve sua primeira edição de publicação em 1991. O material corresponde à tradução, do alemão para o português, de sua tese, realizada na Universidade de Hannover, na Alemanha.

Em seu livro, Kunz (1991) chama a atenção para o "adestramento do movimento humano" que viria ocorrendo nos países ditos "desenvolvidos" e de "terceiro mundo", em relação aos esportes normatizados nos moldes americanos e/ou europeus, sem considerar as culturas do movimento existentes em cada região, estado ou país.

A pesquisa de Kunz (1991) foi organizada em duas partes: a primeira foi uma investigação empírica em forma de estudo de caso, com relação ao ensino da Educação Física em duas realidades escolares diferentes (uma escola particular e uma escola pública), analisando o mundo de movimento de crianças das escolas estudadas. Na segunda parte, o autor segue com o desenvolvimento de concepções teóricas para um novo entendimento de educação e de movimento para a Educação Física brasileira. Nessa última parte, observar-se-ia um dos primeiros sinais acerca de uma abordagem filosófica ao movimento humano, que viria ser conhecida no Brasil como "se movimentar".

O projeto de Elenor Kunz teve início a partir da metade dos anos de 1980, em um período em que, no Brasil, as críticas apresentadas ganhavam dinamismo, enquanto oposição à ditadura civil-empresarialmilitar, instaurada desde o golpe de 1964. Como proposta educacional, os argumentos de Kunz estruturaram-se, inicialmente, em críticas aos moldes dos esportes nas aulas de Educação Física.

Uma das críticas de Kunz (1989) diz respeito à subordinação da Educação Física escolar às instituições esportivas extraescolares em seus códigos, normas e sentidos. Para o autor, o esporte tinha uma posição quase inquestionável, em que essas configurações (de institucionalização desportiva) impediriam que, mesmo o esporte e a cultura do movimento como um todo, pudessem contribuir de maneira mais efetiva em planos de uma educação crítica aos estudantes. 
Diante desse cenário, havia a denúncia do esporte, na escola, enquanto dispositivo biopolítico ${ }^{1}$, estaria suplantando a estrutura disciplinar que, uma vez, havia sido tarefa da ginástica. Nesse caminho, Kunz (1991) recupera as reflexões do grupo de trabalho de Frankfurt (1982) e chama a atenção para o adestramento do movimento nos momentos de Educação Física, que ocorriam com ênfase nas tendências de selecionamento, especialização e instrumentalização emergentes dos princípios da sobrepujança e das comparações objetivas inerentes ao esporte de rendimento.

A crítica encontrava eco, portanto, nas questões envolvendo o ensinar e o aprender. Note-se que Kunz posicionava-se contra um modelo didático de Educação Física centrado no professor. Para o autor, "a ação educacional é uma forma muito especial de interações. Esta ação socialmente regulamentada deveria permitir interações mais bem definidas entre os participantes, ou seja, nesse processo os estudantes deveriam ser considerados como sujeitos nesta ação, pois, somente isto possibilita um processo no horizonte de uma ação comunicativa na educação, esta que é pré-condição indispensável para a mesma" (KUNZ, 1991, p. 138).

Kunz reconhece Freire (1985) ao postular que a verdadeira aprendizagem só se realiza quando o estudante se apropria de um conhecimento, redescobrindo-o e relacionando-o com seu mundo concreto. Observa-se a aprendizagem diretamente relacionada com a forma em que o sujeito relaciona esse conhecimento com seu mundo. "É pelo diálogo que se consegue que o processo da formação da consciência se desenvolva a partir do mundo vivido do educando [...] esta só será possível quando a relação entre professores e alunos tenderem ao sentido horizontal, ao contrário da relação vertical opressora e alienante da concepção bancária de ensino" (KUNZ, 1991, p. 148).

Ao tratar do ensinar e do aprender, Kunz (1991) recupera outros dois conceitos em Paulo Freire, para pensar o fenômeno: educação bancária e libertadora. Não é a intenção, aqui, revisar esse princípio educacional, mas é preciso explicar estas expressões, eixos à crítica feita pelo primeiro autor.

Na educação bancária, não há diálogo, como entende Freire (1985): diálogo é o encontro entre pessoas que nomeiam e, portanto, compartilham o mundo. Na tradição bancária (com vistas ao ensino dos esportes), a comunicação ficaria em segundo plano, e emergiria em lances raros, como em comandos verbais ou por sinais dos professores. Sobre essa percepção de ensino, Kunz (1991) diz:

\footnotetext{
${ }^{1}$ Observa-se que Kunz não trata de biopolítica, esta é uma abordagem ausente na reflexão do autor. Entretanto, isso não impede que, como opção neste trabalho, ela seja empregada no exercício de pensar o cenário. Biopolítica e biopoder são termos que emergiram principalmente de Michel Foucault, filósofo francês que, dentre seus estudos, dedicou-se a investigar a relação entre poder e conhecimento, e como esses estão estritamente relacionados ao corpo. Foucault apresentou essa reflexão em Vigiar e Punir (1975), especialmente quando desenvolve sobre a disciplina e seus processos de dominação. De maneira geral, pode-se dizer que suas teorias presumiram as diversas formas de controle social por meio de instituições sociais, tais como as prisões, hospitais, conventos, instituições educacionais, dentre outras.
} 
Na concepção pedagógica da educação bancária fica evidenciado um conceito de homem que é capaz de se adaptar, de calar e de ser domesticado através da educação e dos interesses da classe dominante (opressora) os quais determinam não só a educação, mas todo o macro sistema social. A função da educação neste sentido consiste em promover a continuidade do processo socializador para preservar a ideologia da classe dominante (p. 135).

A partir dessas premissas Freire (1985) vai explicar que a educação jamais pode ser neutra: conduz à domesticação ou à libertação. Do mesmo modo, seria o ensinar. Para Freire, nossas concepções e ações são posicionamentos políticos ${ }^{2}$.

Em contraponto a essa perspectiva, Freire (1985) elabora uma ideia de educação libertadora. Para o autor, esse método deveria possibilitar a conscientização humana pelo processo de ação comunicativa, possível via um processo de ensino crítico, dialógico e problematizador. Estes elementos seriam capazes de apontar um horizonte ao sujeito, que o levaria a poder alcançar um elevado grau de responsabilidade política, social e reflexiva. Observe-se que essas novas concepções irão pressupor um novo horizonte de ensinar e de aprender na Educação Física.

A seguir, é introduzido ao contexto o "se-movimentar" de Elenor Kunz. Nesse processo, é recuperada uma teoria de movimento humano, de tradição holandesa e alemã, para continuar pensando o diálogo que Elenor Kunz buscou, a partir dessas premissas, com o educador brasileiro Paulo Freire.

\section{ElenorKunz e o "se movimentar"}

Os primeiros estudos filosóficos sobre o movimento humano iniciaram com os professores holandeses Buytendijk e Gordijn, e, dentre os percussores, destacaram-se Jan Tamboer, mais recentemente Peter Heij. Na Alemanha, o principal pesquisador a pensar essa categoria foi Andreas Heinrich Trebels.

Elenor Kunz reconhece que, apesar dos estudos sobre o "se movimentar" terem um pouco mais de 20 anos, ainda há o que se refletir e pesquisar; além disso, identifica que o tema não avançou muito em seus países de origem (KUNZ, 2012).

Segundo Peter Heij (2014), os estudos para uma fundamentação filosófica e pedagógica para o movimento humano iniciaram nos anos 1930, tendo como principais autores Rijsdorp e Gordijn. No ano de

\footnotetext{
2“Se as relações de poder entre professores e alunos devem ser reestruturadas no sentido da ação comunicativa, não se pode negar de que se trata de uma relação de poder, pelo simples fato de que se trata de uma relação de adultos, com mais experiências e que conseguem agir baseados num maior conhecimento teórico [...] também implica, portanto, numa função política de educador, quando - como no nosso caso uma estrutura social dominante é desmascarada pela educação, afim de que a situação de opressão social, econômica e cultural - como da pressão do sistema esportivo pela Educação Física - seja esclarecida, plenamente desvelada. Nisso se justifica plenamente a afirmação de Freire, quando este afirma que a 'educação não pode ser neutra', ou seja: ou ela é instrumento de libertação do homem ou é instrumento de adestramento e opressão” (KUNZ, 1991, p. 157).
} 
1971, segundo Heij, o professor Rijsdorp publicou um livro com o nome de 'Gymnologie', traçando reflexões sobre o movimento humano, importante para pensar a questão do ensinar e do aprender:

Considero fundamental caracterizar o ser humano como um homo se movens, um ser que se movimenta. Por isso a Educação Física não pode partir de exercícios físicos sob comando, mas do movimentar-se humano, também não pode almejar apenas rendimentos físicos, mas a autonomia criativa e autorregulativa do ser humano, essa deve ser a base educacional da Educação Física (RIJSDORP, 1971, apud HEIJ, 2014, p. 5).

Observa-se a presença do protagonismo de quem se movimenta, mas também a denúncia de que por isso, os exercícios, de modo a almejar capacidades físicas, não poderiam ser apenas baseados no comando e repetição, pois o compromisso educacional da Educação Física seria a busca da autonomia criativa do ser humano via movimentar-se.

Com vistas à trajetória desse conceito, ainda segundo Peter Heij (2014), a ideia de relacionalidade teria sido introduzida nos estudos do movimento humano por Buytendijk, o primeiro, na Holanda, a apresentar o movimento como uma forma de conduta, seguidos por Gordijin e Tamboer. Isso significaria dizer que sempre se inclui um "quem" que, ao se movimentar, apresenta uma conduta e um mundo ao qual essa conduta se relaciona. O movimento relacional entre o Homem e mundo é intencional, portanto, é visto pelos autores holandeses como ação/agir. Por isso, partindo deste entendimento, seríamos seres relacionais, pois sempre estamos em relação com algo, com o mundo, pessoas e/ou nós mesmos. Nota-se que todo agir humano pode ser entendido como relações significativas. As discussões quanto ao movimento humano em Trebels $(1992 ; 2003 ; 2006)$ acontece de maneira semelhante, pois o autor passa a conceber o movimento à pessoa que se move, diferente de outras abordagens de pano de fundo cientifico da Educação Física.

Inspirado nesses referenciais, o "se movimentar" é apresentado por Kunz (1991, 2012) como uma dimensão importante na ideia de uma pedagogia da Educação Física, com olhar ao aluno em movimento. Isso significaria ser uma relação entre o protagonista do movimento e o mundo mais complexa que a simples reprodução de movimentos corporais repetitivos pela imitação, como no desenvolvimento de destrezas motoras. Seria preciso atentar-se ao protagonista do movimento, ao contexto da cultura de movimento e aos sentidos e significados resultantes desse "se movimentar".

\section{Paulo Freire e o diagnóstico do cenário educacional brasileiro}

Na pretensão de elaborar uma "Educação Física de brasileiro para brasileiro", Kunz (1991) encontra interlocução com Freire $(1967 ; 1985)$ ao propor como modelo de educação uma perspectiva libertadora, 
com uma abordagem de ensino de viés problematizador. Essa preocupação surge dos dilemas e dificuldades em torno da apropriação e reprodução de um conhecimento de forma descontextualizada, isso é, de sua desconsideração histórico-social. Reiner Hildebrandt-Stramann anunciava as implicações dessa questão em sua estadia no Brasil durante o período de convênio científico Alemanha-Brasil, desde a metade da década de 1980. Nesse caso, a reprodução das referências oriundas da Europa, como no contexto da Educação Física alemã (Sportpädagogik),e da holandesa (Sich bewegen), na realidade brasileira, certamente não faria sentido. O diagnóstico do cenário educacional brasileiro de Paulo Freire contribuiu para reflexão daquele período.

A seguir são apresentadas algumas de minhas interpretações dessa conversa de Elenor Kunz com Paulo Freire, evidenciadas principalmente no primeiro momento de Kunz (1991, 1994), de modo a tentar entender como Elenor Kunz propõe uma teoria do movimento humano a partir do cenário brasileiro.

\subsection{Sobre a ideia de ensino do movimento dialógico-problematizador}

Quando Elenor Kunz refere-se ao termo dialógico, na maioria das vezes, o faz a partir da abordagem dialógica do movimento humano, elaborada por Gordjin e Tamboer. Os dois últimos autores partem de uma compreensão fenomenológica do movimento humano, em que as ações do sujeito do movimento estariam sempre carregadas de um significado, que emergiriam em torno de suas ações no mundo. Por esses elementos apresentados, já se torna possível entender que o objeto em movimento não é o centro da análise, mas sim o ser humano que se movimenta.

Gordjin (apud Tamboer, 1979) retoma e descreve a interdependência do homem e do mundo como um diálogo, e, a partir dessa complexa relação de significados, apresenta possibilidades de transcendência dos limites imaginários entre homem e mundo. É perceptível, nessa concepção protagonizada por Gordjin, o objetivo principal de identificar e evidenciar as diferenças entre um "se movimentar" de sujeitos e o movimento de objetos. Certamente, o movimento também pode ser objeto de análise científica, no entanto, o "se movimentar" tem como horizonte compreender o movimento do ser humano em sua categoria de protagonista, como autor do movimento. Para Trebels (2006), as análises científicas objetivas - sejam em mensurações, comparações, dentre outros - encontram dificuldade nesse quesito.

Sempre quando alguém se movimenta de maneira livre e espontânea, acontece uma relação dialógica desse ato. É dialógico porque, nesse "se movimentar" (base relacional), o ser humano não se move como objeto, mas, por ser constituído de sentidos e significados na ação, faz com que novas aberturas ao mundo sejam possíveis, com diferentes significações e realizações (TAMBOER, 1979). Por isso, Gordjin 
utilizar-se de uma metáfora para dizer que o movimento, nesta interpretação, é um diálogo entre homem e o mundo. O homem coloca diversas questões para o mundo enquanto se movimenta. Essas questões fazem perceber a premissa de que os movimentos não pertencem ao homem, e tão pouco ao mundo, mas são o desenrolar dessa imprevisível relacionalidade.

O movimento não está dado de antemão, configura-se nessa relação do processo dialógico com as coisas do mundo. Parece ser esse um dos insights que Elenor Kunz e Reiner Hildebrandt-Stramann identificam e corroboram os ensinamentos de Paulo Freire, pois, "a forma do movimento nunca já está presente, mas, sim, resulta do processo desse diálogo. No processo de aprendizagem, isto é, no desenvolvimento de uma forma adequada, desenvolve-se um sentido para uma execução de movimento correto ou errado" (HILDEBRANDT-STRAMANN, 2020, p. 10).

Ao pensar sobre a questão da problematização, Kunz apresenta uma passagem ilustrativa da importância do ensino orientado pela problematização no contexto da Educação Física:

A problematização do ensino auxilia desta forma, principalmente, para o rompimento das estruturas rotinizadas das constantes reproduções e ações na Educação Física. Através da mesma pode-se fomentar um processo de permanente criação e descoberta, e para isto ela tem uma importância fundamental, pois na busca de soluções individuais ou coletivas o aluno vivencia um agir de "forma independente", uma cooperação e uma comunicação com o grupo, e com o professor; adquire assim, um saber, experiências e conhecimentos de maior relevância para sua emancipação (KUNZ, 1991, p. 192).

E ainda:

Em relação à problematização do ensino que envolve o movimento, os alunos devem encontrar possibilidades de solucionar problemas a partir de suas próprias experiências e vivências. 'O educando deve agir pela auto estimulação'. A única pré-condição para isto é que o problema a ser solucionado deve ser muito bem esclarecido anteriormente (KUNZ, 1991, p. 193).

A orientação do ensino pela problematização parte da ideia de que os movimentos precisam passar por um processo de construção, de estratégias de criação, descobertas e questionamentos. Problematizar a temática referida significa envolver necessariamente a análise da realidade "que vai desvelando com a superação do conhecimento puramente sensível dos fatos pela razão de ser dos mesmos" (FREIRE, 1967, p. 19).

Com caráter de síntese, o trecho a seguir representa o núcleo do que seria, e do que se pretende ao se propor uma aprendizagem do "se movimentar", a partir de um ensino dialógico-problematizador:

A aprendizagem do "se-movimentar" não se orienta no ensino das destrezas técnicas e fechadas, padronizadas do movimento humano, mas abre perspectivas para um redimensionamento e uma apreensão abrangente de campos de atuação pelo "movimento dialógico". O que deverá ser percebido no momento da construção/elaboração deste campo 
de atuação pelos participantes do processo é o sentido/significado deste "se-movimentar". Desta forma, o "se-movimentar" torna-se um diálogo entre homem e mundo que exige uma inter-relação dialética entre subjetividade e objetividade, sem jamais nuclear-se para nenhuma destas posições extremas. [...] Para Freire, a aprendizagem não deve ser uma transmissão de informações, técnicas, mas deve ser um processo dinâmico, vivo, que se realiza pelo diálogo com todos os participantes do processo e relacionado sempre a situações locais e às vivências, experienciais existenciais dos educandos (KUNZ, 1991, p. 180).

Desse modo, a passagem acima fornece elementos para compreender que a aprendizagem do "se movimentar" não se encaixa numa perspectiva orientada em princípios que supervalorizem o movimento fechado, padronizado e bancário, até porque, nesse entendimento, o movimento é um processo dialógico. Portanto, são atos dinâmicos, pois envolvem sujeitos e suas ações, incorporando suas próprias experiências e olhares do mundo.

\section{Considerações finais}

As problemáticas do ensinar e do aprender sempre atravessaram a área da Educação Física. Desde o advento do que se convencionou chamar de "movimento renovador", várias reflexões foram arregimentadas para pensar os dilemas desse campo de conhecimento.

Nesse processo, Elenor Kunz apresenta, a partir de seus primeiros livros (1991; 1994), nova maneira de pensar a questão do movimento humano em cenário brasileiro, incluindo uma nova perspectiva de educação.

A ideia de teoria do movimento humano, incorporada pela tradição holandesa de movimento próprio (Sich bewegen) e da concepção dialógica de movimento, mostraram-se chave para repensar e reformular uma tradição de ensino e aprendizagem na Educação Física brasileira, afastando-se do que Paulo Freire nomeou de educação bancária.

Assim, para poder pensar tais abordagens no contexto do Brasil, Kunz encontrou interlocução com o educador Paulo Freire, que vinha, refletindo acerca da educação brasileira.

Como observado, Kunz inspirou-se em conceitos importantes de Freire para pensar a questão do ensino do movimento. Vimos, nos textos, alguns deles, como o de educação bancária, educação libertadora e a proposta via problematização dos conteúdos.

Kunz (1991) evidencia a ideia de uma aprendizagem do "se movimentar" a partir de um ensino dialógico-problematizador, que, nessa leitura, considera o ato dialógico do movimento e, também, a ação 
de problematizar os conteúdos, de maneira a ser seja possível abertura de interpretação por aquele que o examina.

Por fim, a ideia de ensino dialógico-problematizador propõe uma abordagem de movimento que o considere a partir do "se movimentar", capaz de, no processo de ensinar e aprender, problematizar questões envolvendo a cultura de movimento, ou seja, desde a indústria esportiva ao próprio "se movimentar".

\section{Referências}

FRANKFURTER ARBEITSGRUPPE (HRSG.).Offener Sportunterricht - Analy-Sieren Und Planen. Reinbek, 1982.

FREIRE, Paulo. Educação como prática de liberdade. Rio de Janeiro: Paz e Terra, 1967.

.Pedagogia do Oprimido. 14.ed. Rio de Janeiro: Paz e Terra, 1985.

Terra, 1996.

. Pedagogia da autonomia: saberes necessários à prática educativa. São Paulo: Paz e

FOUCAUlT, Michel. Vigiar e Punir: nascimento da prisão; tradução de Raquel Ramalhete. 42. ed. Petrópolis, RJ: Vozes, 2014.

HEIJ, Peter. Begründungen eine Verantwortungs Bewegungsunterricht. Budel, Nederland: Damon, 2006. (Tradução do holandês para o alemão por Andreas H. Trebels em 2009, e do alemão para o português por ElenorKunz em 2014).

HILDEBRANDT-STRAMANN, Reiner. Ação dialógica na Educação Física: considerações educacionais teóricas e pedagógicas de movimento. Motrivivência, [S.L.], v. 32, n. 63, p. 01-16, 5 ago. 2020. Universidade Federal de Santa Catarina (UFSC). http://dx.doi.org/10.5007/2175-8042.2020e72870.

KUNZ, Elenor. O esporte como conteúdo hegemônico da Educação Física escolar. Ijuí:Contexto\& Educação, 1989.

Educação Física: ensino \& mudanças. Ijuí: Unijuí, 1991. [Coleção Educação Física, 3 ed. 2012].

Transformação didático-pedagógica do esporte. Ijuí: Unijuí, 1994. [Coleção Educação Física, 8 ed. 2014].

Por uma concepção teórico-filosófica do Movimento Humano. In: anais. V Colóquio de pesquisa qualitativa em Motricidade Humana: Motricidade, Educação e Experiência, 5. 2012, São Carlos, p.59-67.

SOARES, Carmen Lúcia et al. Metodologia do ensino de Educação Física. São Paulo: Cortez, 1992.

TREBELS, Andreas Heinrich. Plaidoyer para um diálogo entre teorias do movimento humano e teorias do movimento no esporte. Rev. Bras. Ciên. Esp., Campinas, v. 13, n. 3, p. 338-344, maio, 1992. 
.Uma concepção dialógica e uma teoria do movimento humano. Perspectiva. v. 21, n. 1, p. 249-267, jan. /jun. 2003.

A concepção dialógica do movimento humano: uma teoria do "semovimentar". In: KUNZ, E.; TREBELS, A. H. (Org.). Educação física crítico emancipatória:com uma perspectiva da pedagogia alemã do esporte. Ijuí: Ed. Unijuí, 2006.

TAMBOER, Jan W. I. Movimentar-se: um diálogo entre o homem e o mundo. Revista Pedagógica do Esporte, Hamburgo, v. 3, n. 2, p. 14-29, março 1979. [Tradução do Grupo de Trabalho Pedagógico UFSM/UFPE, 1986]. [Sich-bewegen: ein Dialog zwischen Mensch und Welt in: Sportpädagogik].

\section{Como citar este artigo}

SIQUEIRA, B. N. Sobre a ideia de ensino do movimento dialógico-problematizador: para pensar o "se movimentar". Revista Kinesis, Santa Maria, v. 39, p. 01-11, 2021.

* O presente trabalho não contou com apoio financeiro de nenhuma natureza para sua realização. 